\title{
A CONCEPÇÃO COMUNICATIVA DA EDUCAÇÃO NA PERSPECTIVA DE JÜRGEN HABERMAS: A DIMENSÃO INTERSUBJETIVA DA EXPERIÊNCIA FORMATIVA
}

\author{
THE COMMUNICATIVE CONCEPTION OF EDUCATION IN THE PERSPECTIVE OF JÜRGEN \\ HABERMAS: THE INTERSUBJECTIVE DIMENSION OF FORMATIVE EXPERIENCE
}

Bruno Luciano de Paiva Silva*

\begin{abstract}
RESUMO
Uma subjetividade tecida pela intersubjetividade elucida o tema proposto pelo presente artigo, a saber, de se pensar uma concepção comunicativa de educação a partir de Habermas. A nossa hipótese é de que a dimensão intersubjetiva, desenvolvida pelo filósofo alemão, renova o conceito de experiência formativa, ao recuperar seu caráter crítico e emancipatório e por propor uma práxis dialógica para a ação pedagógica. Assim, o escopo principal será analisar a configuração da concepção comunicativa da educação na perspectiva habermasiana. Desse modo, o artigo está dividido em duas partes: (a) na primeira, apontaremos o contexto (guinada linguístico-pragmática; razão comunicativa; mundo da vida) em que a educação se insere; (b) para analisar, no segundo momento, de que forma se edifica o conceito comunicativo da educação, oferecendo uma alternativa para o problema da formação humana. A escolha do tema se justifica por contrapor à racionalidade instrumental que, desde a implantação da tendência tecnicista na educação brasileira, promovida pelos governos militares (1964-1985), vem orientando a experiência no Brasil.

PALAVRAS-CHAVE: Razão comunicativa. Mundo da vida. Educação. Jürgen Habermas.
\end{abstract}

\begin{abstract}
A subjectivity woven by intersubjectivity elucidates the theme proposed by the present article, namely, to think about a communicative conception of education from Habermas. Our hypothesis is that the intersubjective dimension, developed by the German philosopher, renews the concept of formative experience by recovering its critical and emancipatory character and by proposing a dialogic praxis for pedagogical action. The present article investigates, from the philosophy of Jürgen Habermas, the construction of a communicative conception of education. In this way, the article is divided into two parts: (a) in the first one, we will point out the linguistic context (linguistic-pragmatic guise, communicative reason, world of life) that education is inserted; (b) to analyze, in the second moment, how the communicative concept of education is built, offering an alternative to the problem of human formation. The choice of theme is justified by opposing the instrumental rationality that, since the implantation of the technicist tendency in Brazilian education, promoted by the military governments (1964-1985), has guided the experience in Brazi
\end{abstract}

KEY-WORDS: Communicative Reason. World of Life. Education. Jürgen Habermas

\footnotetext{
${ }^{*}$ Mestre em Filosofia (FAJE) e doutorando em Filosofia (UFMG). Professor de Filosofia e Sociologia do Centro Universitário Newton Paiva. E-mail: brunopaiva1818@gmail.com.
} 


\section{INTRODUÇÃO}

Ao receber o Prêmio Kyoto, em 11 de novembro de 2004, Habermas diz em seu discurso: "Tenho a imagem de uma subjetividade a ser representada como se fora uma luva virada do avesso, a qual põe à mostra a estrutura de suas malhas tecidas com os fios da intersubjetividade" (HABERMAS, 2007, p. 26). A metáfora de uma subjetividade tecida pela intersubjetividade elucida o tema proposto pelo presente artigo, a saber, de pensar uma concepção comunicativa de educação a partir de Habermas. A nossa hipótese é de que a dimensão intersubjetiva, desenvolvida pelo filósofo alemão, renova o conceito de experiência formativa, ao recuperar seu caráter crítico e emancipatório e por propor uma práxis dialógica para a ação pedagógica. Assim, o escopo principal será analisar a configuração da concepção comunicativa da educação na perspectiva habermasiana. Com isso, o artigo está dividido em duas partes: (a) na primeira, apontaremos o contexto linguístico (guinada linguísticopragmática; razão comunicativa; mundo da vida) em que a educação se insere; (b) para analisar, no segundo momento, de que forma se edifica o conceito comunicativo da educação, oferecendo uma alternativa para o problema da formação humana. A escolha do tema se justifica por contrapor à racionalidade instrumental que, desde a implantação da tendência tecnicista na educação brasileira promovida pelos governos militares (1964-1985), vem orientando a experiência formativa e permitir que o outro, a alteridade, seja protagonista na formação de todo educando, criando nele a responsabilidade e solidariedade por outrem.

\section{A CONCEPÇÃO COMUNICATIVA DA EDUCAÇÃO: RAZÃO COMUNICATIVA, MUNDO DA VIDA E DISCURSO}

\subsection{Razão comunicativa e mundo da vida}

O ponto de partida da filosofia da consciência está na "auto referência de um sujeito que representa e manipula objetos" (HABERMAS, 1990b, p. 32), ou seja, os entes do mundo se convertem, por meio da razão moderna, em objetos manipuláveis. É por isso que o paradigma da filosofia da consciência caracteriza-se por uma racionalidade que transforma os objetos do mundo em objetos de conhecimento. A filosofia da consciência passou a ser questionada por meio de desenvolvimentos históricos como, por exemplo, o advento de um novo tipo de racionalidade metódica que questiona o privilégio atribuído ao conhecimento filosófico; e ao surgimento da crítica contra a reificação e a funcionalização de formas de vida e de 
Artigo: A concepção comunicativa da educação na perspectiva de Jürgen Habermas: a dimensão intersubjetiva da experiência formativa

relacionamento que se assentam nas relações sujeito-objeto. Esses acontecimentos foram aos poucos, segundo o filósofo alemão, preparando para uma importante transformação no interior da filosofia, a guinada linguística. Além disso, a possibilidade de evidência prélinguística, ou seja, de um acesso direto aos fenômenos da consciência, afirmada pela filosofia da consciência, é questionada pela guinada linguística. A filosofia da linguagem parte, segundo Habermas, de uma análise das expressões linguísticas para reconstruir racionalmente o conhecimento das regras gramaticais. A linguagem é um elemento fundamental, nesse contexto, na constituição de nosso conhecimento. Todo esse conhecimento do mundo, por exemplo, é linguisticamente mediado, ou seja, desaparece a ideia de sujeito solitário que se volta para os objetos manipuláveis do mundo. Nesse sentido, a mediação linguística ocorre até na relação do sujeito consigo mesmo. O próprio ato de pensar já pressupõe linguagem e, efetivamente, a comunidade ilimitada de comunicação. O próprio ato de pensar, para ter sentido e validade, deve estar em condições de justificar-se. Assim, a filosofia da linguagem mostra que a linguagem não é apenas um instrumento de comunicação, mas um elemento constitutivo de nosso conhecimento. A partir dessa afirmação, constatamos que o mundo da vida já está sempre interpretado pela linguagem. Os indivíduos, por um lado, "encontram-se num mundo aberto e estruturado linguisticamente e se nutrem de contexto de sentido gramaticalmente pré-moldados" (HABERMAS, 1990b, p. 52) e, por outro lado "o mundo da vida, aberto e estruturado linguisticamente, encontra o seu ponto de apoio somente na prática de entendimento de uma comunidade de linguagem." (HABERMAS, 1990b, p. 32). A guinada linguística apresentou a linguagem como médium constitutivo e intransponível de todo sentido e validade. É assim que Habermas mostrou a necessidade da passagem da filosofia da consciência para a filosofia da linguagem. No entanto, a guinada linguística, num primeiro momento, estaria limitada ao estudo da dimensão semântica da linguagem, e, com isso, sem levar em conta as relações que se estabelecem entre os sujeitos. Por isso, Habermas propõe, como complemento à primeira guinada, a guinada pragmática, como já destacamos neste artigo. A guinada linguística priorizou, fundamentalmente, a dimensão semântica da linguagem, ou seja, as relações dos sinais com o significado. E nesse sentido, a análise semântica reproduziu o esquema da relação sujeito-objeto, da filosofia da consciência, pois se limitava à análise da relação entre sentenças (linguagem) e estado-de-coisas (mundo). Desse modo, o estudo da dimensão semântica da linguagem negligenciou, segundo Habermas, o conjunto da comunicação. Nesse sentido, o estudo da dimensão pragmática da linguagem amplia a solução do paradigma (linguagem) a partir do momento em que se apoia numa 
relação de três termos - linguagem, mundo e participantes de uma comunidade linguística -, portanto, a relação sujeito-objeto, que era uma relação monológica, passa a ser uma relação dialógica. A partir da análise da dimensão pragmática da linguagem, isto é, a linguagem enquanto forma de comunicação, constatou que o uso de sentenças com uma intenção comunicativa buscava alcançar um entendimento sobre algo. Assim, segundo Habermas, alcançar entendimento sobre algo é o objetivo fundamental da fala humana. Com isso, o entendimento visa "a produção de um acordo, que termina na comunidade intersubjetiva da compreensão mútua, do saber compartilhado, da confiança recíproca e da concordância de uns com os outros. O acordo descansa sobre a base do reconhecimento de quatro correspondentes pretensões de validades: inteligibilidade, verdade, correção e sinceridade" (HABERMAS, 1989a, p. 301).

A guinada pragmática mostrou que a linguagem é o médium intransponível de todo sentido e validade e que a linguagem enquanto médium realiza três funções: 1) a função expressiva, que serve para expressar as intenções de um falante; 2) a função representativa, que apresenta estados de coisas; e 3) a função interpelativa, que estabelece relações intersubjetivas. Assim, a linguagem sempre mediatiza a relação significante entre sujeitoobjeto e, consequentemente, toda relação sujeito-sujeito. A linguagem entendida nessa dimensão pragmática implica um entendimento sobre algo, isto é, implica um entendimento sobre os sentidos das palavras usadas e sobre o sentido do ser das coisas medidas pelos significados das palavras. Com isso, a dimensão pragmática da linguagem já está presente no uso dos sinais de uma língua, em outras palavras, na relação dos sinais com o sujeito e com o uso que eles fazem dos sinais. Assim, constatamos que todo ato de fala tem uma dupla estrutura performativo-proposicional: 1) um elemento performativo que estabelece uma forma determinada de comunicação e nesse plano intersubjetivo, falante e ouvinte estabelecem mediante atos ilocucionários, relações que permitem entender-se entre si; 2) e um elemento proposicional que constitui o conteúdo da comunicação em que, nesse plano de experiência e estados de coisas, falante e ouvinte buscam entender-se sobre algo mediante a função fixada por (1). Sob essa perspectiva, toda proposição envolve uma atitude comunicativa, que nos relaciona com os outros indivíduos, e uma atitude semântica - referencial, que nos relaciona com algo do mundo. Sendo assim, "os participantes de um diálogo, ao satisfazer a dupla estrutura de fala, têm que comunicar simultaneamente em ambos os níveis, tem que unir a comunicação de um conteúdo com a comunicação acerca do sentido em que se emprega o conteúdo comunicado". (HABERMAS, 1989a, p. 342) 
Artigo: A concepção comunicativa da educação na perspectiva de Jürgen Habermas: a dimensão intersubjetiva da experiência formativa

A dupla estrutura de todo ato de fala revela um elemento fundamental da linguagem: “a reflexividade que é inerente à linguagem” (HABERMAS, 1989a, p. 342), isto é, as linguagens naturais possuem uma autorreflexividade própria. Elas possuem uma capacidade de se autoexplicar e de se autointerpretar. Assim, em todo ato de fala, os participantes precisam, ao comunicarem-se nos dois planos, no ilocucionário e no proposicional, buscar a manutenção contínua de uma coerência entre eles. Portanto, toda proposição envolve uma atitude comunicativa, que nos relaciona com os outros indivíduos, e uma atitude semântica referencial, que nos relaciona com algo do mundo. Para Habermas, a virada linguísticopragmática da filosofia mostrou que na estrutura da linguagem está presente uma exigência de racionalidade, a partir do momento em que o falante, ao se comunicar com o ouvinte dentro da comunidade linguística, buscar o entendimento sobre algo. Assim, é preciso uma nova racionalidade que permita o acordo racional e dialógico entre os sujeitos: a razão comunicativa. O resultado da virada linguístico-pragmática foi, segundo Habermas, o aparecimento de uma nova racionalidade: a razão comunicativa. Ela supera a racionalidade instrumental da filosofia da consciência, que centrada no sujeito, proporcionava um controle instrumental sobre a natureza, a partir do momento que busca o entendimento mútuo e, promove um acordo racional entre os sujeitos. Para a filosofia da consciência, a racionalidade é medida, por um lado, pela maneira como a subjetividade solitária se orienta pelas suas representações e, por outro, pelos critérios de verdade que regulam as relações do indivíduo que conhece e age segundo fins com o mundo de objeto. A filosofia da linguagem concebe o saber como algo mediado pela comunicação e, por isso, entende a racionalidade como a capacidade que os sujeitos, que participam de uma interação comunicativa, têm de orientar-se por pretensões de validade. Logo, um sujeito se exprime racionalmente, segundo Habermas, quando se orienta performaticamente por pretensões de validade. Com isso, esse sujeito não se comporta apenas de modo racional, mas é, sobretudo, racional, pois pode justificar seu agir por pretensões de validade.

Quais são, então, as pretensões de validade que o sujeito levanta com os seus atos de fala? Para Habermas, em todo ato de fala estão presentes quatro pretensões de validade: pretensão à compreensibilidade, pretensão à verdade, pretensão à correção normativa e pretensão à sinceridade. Ao se relacionar com os mundos objetivo, social e subjetivo, o sujeito levanta para cada um desses mundos uma determinada pretensão de validade. Ele espera, ao relacionar-se com o mundo objetivo, que o conteúdo proposicional do seu ato de fala seja aceito como verdadeiro; ao relacionar-se com o mundo social, deseja que suas manifestações 
sejam aceitas como corretas e, ao relacionar-se com o mundo subjetivo, espera que suas intenções sejam consideradas sinceras. A pretensão à compreensibilidade diz respeito a determinada competência de regra que dispomos, ou seja, o nosso enunciado será compreensível ao ouvinte quando ele for bem formado gramaticalmente e pragmaticamente. Assim, a pretensão à compreensibilidade só pode ser satisfeita quando falante e ouvinte dominarem a mesma língua. Quando acontece o contrário, de falante e ouvinte não falarem a mesma língua, será necessário, segundo Habermas, um esforço hermenêutico para alcançar um esclarecimento semântico. Se falante tem a intenção de comunicar um conteúdo proporcional verdadeiro, ele levanta a pretensão à verdade; já na pretensão à sinceridade, o falante tem de querer expressar suas intenções de forma veraz, para que o ouvinte possa crer em sua manifestação; e, por último, os mandamentos, os processos, os conselhos, isto é, as manifestações normativas orientadas, implicam pretensão à correção. Além disso, os atos de fala proferidos pelo falante não podem ser aceitos parcialmente pelo ouvinte, mas devem basear sua validade em algumas condições, a saber: (1) a oração deve obedecer às estruturas gramaticais aceitas; (2) o enunciado deve ser verdadeiro; (3) a intenção do falante deve ser veraz; (4) e a manifestação deve ser normativamente correta. É por isso que o ouvinte pode, diante do ato de fala do falante, recusar, indagar ou aceitar. $\mathrm{O}$ falante, ao se comunicar com um ouvinte, visa se fazer entender a respeito de algo. Esse entendimento, segundo Habermas, "é o processo de construção de um acordo sobre a base pressuposta das pretensões de validade reconhecidas em comum". (HABERMAS, 1989a, p. 301). Esse acordo entre os participantes fundamenta-se sobre a base das quatro pretensões de validade. Então, a racionalidade comunicativa compõe-se de pretensões de validade que se resolvem discursivamente. Passaremos, agora, ao conceito de mundo da vida.

As pretensões de validade que o falante levanta com seus atos de fala não estão situadas fora do mundo, mas, no mundo da vida. O mundo da vida como um saber não temático está, segundo Habermas, de modo implícito e pré-reflexivo. Assim, ele "é algo que todos nós temos sempre presente, de modo intuitivo e não problemático, como sendo uma totalidade pré-teórica, não-objetiva - como esfera das auto evidências cotidianas, do common-sense" (HABERMAS, 1989a, p. 92). O mundo da vida caracteriza-se como certeza imediata, como força totalizante e pelo holismo do saber que serve como pano de fundo. Enquanto uma certeza imediata, o mundo da vida "mostra-se como uma forma intensificada e, não distante, deficiente, do saber" (p. 92). Como força totalizante, o mundo da vida "forma uma totalidade que possui um ponto central e limites indeterminados, porosos e, mesmo assim, 
Artigo: A concepção comunicativa da educação na perspectiva de Jürgen Habermas: a dimensão intersubjetiva da experiência formativa

intransponíveis, que vão recuando" (p. 92). Por último, o mundo da vida, enquanto holismo, se torna emaranhado, ou seja, "nele os componentes encontram-se liquefeitos". (p. 93) Mas quais são os elementos que se encontram emaranhados no mundo da vida? Para Habermas, o mundo da vida estrutura-se a partir da cultura, da sociedade, das estruturas de personalidade e da linguagem. Conforme Habermas (1989a, p. 96), cultura "é o armazém do saber, do qual os participantes da comunicação extraem interpretações no momento em que se entendem mutuamente sobre algo". Assim, a cultura está encarnada em formas simbólicas que são, por sua vez, transmitidas pela tradição. É por meio da tradição que o ethos de cada grupo social se exprime. Por isso, esse elemento do mundo da vida mereceu um destaque maior de Habermas, pois é a partir da cultura, como acervo do saber (tradição), que foi permitida a análise genealógica do teor cognitivo da moral. A sociedade, por sua vez, "compõe-se de ordens legítimas através das quais os participantes da comunicação regulam sua pertença a grupos sociais e garantem solidariedade" (HABERMAS, 1989a, p. 96). Por último, Habermas identifica "entre as estruturas de personalidade todos os motivos e habilidades que colocam um sujeito em condições de falar e de agir, bem como de garantir sua identidade própria”. Portanto, o mundo da vida é o horizonte não questionado e não problematizado no qual os sujeitos das interações dialógicas se movem para se comunicar. Dessa forma, os componentes do mundo da vida - a cultura, a sociedade e as estruturas da personalidade - formam, segundo Habermas, "conjuntos de sentido complexos e comunicantes, embora estejam incorporados em substratos diferentes". Logo, as práticas comunicativas cotidianas se estendem sobre a cultura, a sociedade e sobre as estruturas da personalidade, "constituindo o meio através do qual se forma e se reproduz a cultura, a sociedade e as estruturas de personalidade" (HABERMAS, 1989a, p. 96). A linguagem, segundo o autor, desempenha uma função importante no mundo da vida. Ela é o médium de constituição e reprodução das estruturas do mundo da vida. Além disso, tem como função buscar o entendimento mútuo, coordenar as ações e promover a socialização. Desse modo, as estruturas do mundo da vida são reproduzidas por meio da continuação do conhecimento válido, estabilização da solidariedade de grupo e da socialização de atores responsáveis.

Os elementos do mundo da vida não são sistemas que formam ambientes uns para os outros, mas eles interagem entre si por meio da linguagem. Os sistemas de ação, por exemplo, responsáveis pela reprodução cultural (escolas), pela integração social (direito) ou pela socialização (família), não funcionam como sistemas separados. Elas interagem, por meio da linguagem, mantendo a totalidade do mundo da vida. $\mathrm{O}$ mundo da vida possui, segundo 
Habermas, um status diferente dos conceitos formais de mundo. Ele é "o lugar transcendental no qual falante e ouvinte saem ao encontro; em que podem colocar-se reciprocamente a pretensão de que seus proferimentos concordam com o mundo" (HABERMAS, 2003, p. 179, tradução nossa). Desse modo, o que distingue o mundo da vida dos conceitos formais de mundo está no fato de que o entendimento é constitutivo do mundo da vida, enquanto que os conceitos formais de mundo formam, segundo Habermas, um sistema de referência para aquilo cujo entendimento é possível. Vimos que a virada linguístico-pragmática, que resultou em uma nova racionalidade (a razão comunicativa) situada no mundo da vida, permitiu a Habermas a construção de um novo marco teórico que possibilitará, consequentemente, a elaboração de uma nova resposta ao problema do Ensino de Filosofia.

\subsection{A dimensão intersubjetiva da educação}

Quando analisa, em sua obra, os processos de individualização e socialização e seus paradoxos na contemporaneidade, Habermas abre espaço para enfrentar os desafios da educação; e, ao conceber a formação do indivíduo, através de processos interativos, permite uma compreensão da relação entre o eu e o outro no interior de uma estrutura de reconhecimento recíproco e de aprendizagem mútua. Nesse sentido, o modo como o autor enfrenta a questão da alteridade torna significativo para fomentar o debate sobre questões éticas, sobretudo se é possível à experiência formativa fazer jus à singularidade de outrem. Por isso, temos o objetivo de investigar, na filosofia habermasiana, a relação de proximidade entre alteridade e formação humana. Na Teoria do agir comunicativo, o filósofo configura a alteridade para além das fronteiras de uma subjetividade que tende a submetê-la, ao estabelecer os princípios teóricos que indicam a questão do outro num processo relacional. Em outra obra, Inclusão do outro, Habermas reafirma, agora em âmbito político, uma moral baseada no respeito por todos e na responsabilidade solidária de cada um para com todos como condição de realização das sociedades pluralistas. Esse objetivo, de o sujeito ser responsável por outrem, só é possível através de um processo educacional que forme indivíduos para o reconhecimento da alteridade, por meio de uma rede de relações intersubjetivas e de fortes laços sociais. Através da renovação do conceito de formação, a partir de elementos da filosofia habermasiana, é possível, segundo Nadja Hermann (2014, p. 95), destacar dois aspectos que enriquecem a dupla determinação entre formação e reconhecimento do outro, mediante a valorização do discurso e do diálogo. 
Artigo: A concepção comunicativa da educação na perspectiva de Jürgen Habermas: a dimensão intersubjetiva da experiência formativa

A experiência formativa interpretada pela intersubjetividade permite retomar a metáfora de Habermas, de uma subjetividade construída pela relação com outrem, onde cada indivíduo se constitui no processo de interação social, por meio da racionalidade comunicativa. O outro, que já se encontra pressuposto na interação comunicativa, abre espaço para que se apresentem razões e argumentos em situações problemáticas sobre as orientações de nossas vidas, ganha relevância. Para localizar o outro nos momentos interativos, se faz necessário diferenciar os conceitos de agir comunicativo e de discurso. $\mathrm{O}$ agir comunicativo, categoria central na Teoria do agir comunicativo, refere-se às ações interativas realizadas entre dois ou mais indivíduos, mediados pela linguagem, que efetuamos em nossas práticas cotidianas. Esse agir pressupõe a linguagem como medium para o entendimento sobre os fatos do mundo objetivo, as normas sociais e a nossa própria subjetividade. A ação comunicativa se dá de forma implícita no mundo da vida pela aceitação ou rejeição daquelas pretensões de validez que são colocadas pelo outro. Trata-se de um conjunto de comunicações não problematizadas, que orientam nosso agir, que compartilhamos em comunidade. No entanto, quando uma pretensão de validade não é aceita, passa para outro plano da comunicação denominado por Habermas de discurso. Quando nossas crenças e certezas perdem a sua evidencia natural, torna-se objeto de discussão a respeito de sua validade no processo argumentativo, em que a força do melhor argumento produzirá um novo consenso. Aquelas evidências que sempre alimentavam nossas decisões e escolhas perdem seu reconhecimento e validade, e o discurso, que é o âmbito em que se dispunha o melhor argumento, produz sem qualquer forma de coerção o consenso racional da situação. $\mathrm{O}$ agir comunicativo e o discurso buscam o mesmo fim, o entendimento mútuo, mas mantem especificidades próprias. $\mathrm{O}$ diálogo, por outro lado, pode ser entendido nesse contexto como uma conversa recíproca entre duas ou mais pessoas.

Os diferentes momentos do agir comunicativo, tanto o diálogo quanto o discurso, permitem destacar o tema da alteridade na constituição da estrutura da autoconsciência e na possibilidade de despertar para o reconhecimento intersubjetivo, decisivo na formação humana. A autoconsciência não se realiza a partir de uma subjetividade isolada, mas depende de uma alteridade para constituir-se, e está presente tanto no diálogo como no discurso. A possibilidade dos processos dialógicos e discursivos ampliarem nosso reconhecimento intersubjetivo se concretiza no reconhecimento de que o outro, que se encontra diante de nós, é possuidor da mesma igualdade de condições de fala. A importância dos processos interativos, que nos colocam diante da diferença, consiste no confronto com outras 
perspectivas, levando-nos a despertar o reconhecimento intersubjetivo para aquilo que ultrapassa nossa visão de mundo, num constante aprendizado de ampliação da nossa sensibilidade. Apesar de as crianças ainda não terem amadurecido sua competência comunicativa e não poderem participar no sentido puro e restrito de um discurso, elas podem ser educadas numa perspectiva comunicativa e dialógica. Os ganhos são inúmeros nesta perspectiva: as crianças partem do reconhecimento de si e do outro como participantes da mesma comunidade de comunicação que merecem igual respeito e consideração; desencadeia processos de aprendizado de caráter argumentativo racional; preparam para o reconhecimento do outro; familiariza a ideia de que a verdade depende das relações intersubjetivas e de argumento. Entretanto, surgirá também nesse contexto de comunicação dissensos, malentendidos, erros, mas que têm um teor pedagógico de permitir a confrontação com os limites de nossa interpretação, com a possibilidade de o outro estar certo, isto é, aqui há uma restrição aos procedimentos autoritários ${ }^{1}$ na relação com o conhecimento, com relação à ciência e com a moral. De acordo com Hermann (2014, p. 101),

Processos formativos, que preparam a capacidade argumentativa, dispõem de melhores condições para a formação de mentalidades abertas e não dogmáticas, com importantes desdobramentos para uma futura inserção na esfera pública. O confronto com o outro, com outras culturas, faz o homem refletir sobre sua própria situação, levando-o a ultrapassar os limites de uma compreensão paroquial.

A “inclusão do outro", proposta por Habermas, depende do reconhecimento e da solidariedade, que não surgem espontaneamente do direito, mas depende de um processo educativo sólido que conduza ao sentimento de pertença a uma comunidade e valores-normas compartilhados de um modo comum, para o qual o estímulo do reconhecimento intersubjetivo ganhe relevância. Assim, a sensibilidade pelo outro e a internalização da consciência moral permitem o reconhecimento da dependência que temos uns dos outros e de nossas fragilidades, passíveis de satisfação apenas pela integração social. Portanto, o convite por propostas inclusivas, que evitem distorções e a denegação de reconhecimento "quando uma cultura majoritária, no exercício do poder político, impinge as minorias a sua forma de vida,

\footnotetext{
${ }^{1}$ A proposta de uma concepção comunicativa da educação, na perspectiva habermasiana, se constrói em outros caminhos. A formação do indivíduo pela socialização, por exemplo, reflete, por um lado, a tradição humanista de Humbolt, que entende a formação do espírito humano como resultado de um trabalho de si mesmo e, por outro lado, a tradição democrática da educação de Dewey, que associa a ideia de que a educação é vital para a produção da vida democrática.
} 
Artigo: A concepção comunicativa da educação na perspectiva de Jürgen Habermas: a dimensão intersubjetiva da experiência formativa

negando assim aos cidadãos de origem cultural diversa uma efetiva igualdade de direitos" (HABERMAS, 2002, p.170), depende de uma concepção comunicativa da educação.

\section{CONCLUSÃO}

Vimos, ao longo do percurso, que o conceito de formação humana foi ampliado a partir da ênfase no aspecto intersubjetivo da práxis educativa dentro de um contexto pósmetafísico. Inicialmente, apresentamos a guinada linguístico-pragmática na filosofia de Habermas, permitindo ao filósofo contrapor a racionalidade instrumental ao paradigma da filosofia da consciência, a partir do conceito de razão comunicativa e de mundo da vida. No segundo momento do artigo, a partir de um novo contexto em que a educação se insere, propusemos explicitar a concepção comunicativa da educação, a partir de uma prática educacional que estimule o reconhecimento intersubjetivo e a responsabilidade pelo outro. Se Habermas vê a subjetividade tecida pelos fios da intersubjetividade, cabe à Educação estimular cada indivíduo, por meio de práticas discursivas e dialógicas, tecer um ser humano preparado para os desafios de respeitar toda forma de alteridade e de construir um mundo mais justo e fraterno.

\section{REFERÊNCIAS}

DUTRA, Delamar José Volpato. Razão e consenso: uma introdução ao pensamento de Habermas. Pelotas: UFPEl. 1993.

DUTRA, Delamar José Volpato. Kant e Habermas: A reformulação discursiva da moral Kantiana. Porto Alegre: EDIPUCRS. 2002.

HABERMAS, Jürgen. A crise de legitimação no capitalismo tardio. Rio de Janeiro: Tempo Brasileiro. 1980.

HABERMAS, Jürgen. Teoría de la acción comunicativa: complementos y estudios previos. Madrid: Cátedra. 1989a.

HABERMAS, Jürgen. Consciência moral e agir comunicativo. Rio de Janeiro: Tempo Brasileiro. 1989b.

HABERMAS, Jürgen. Pensamento pós-metafísico. Rio de Janeiro: Tempo Brasileiro. 1990b.

HABERMAS, Jürgen. O discurso filosófico da modernidade. São Paulo: Martins Fontes. 1990a. 
HABERMAS, Jürgen. A inclusão do outro: estudos de teoria política. Tradução de George Sperber et al. São Paulo: Loyola. 2002.

HABERMAS, Jürgen. Teoría de la acción comunicativa, I: racionalidade de la acción y racionalización social. Tradução de Manuel Jiménez Redondo. Madrid: Taurus. 2003a.

HABERMAS, Jürgen. Teoría de la acción comunicativa II: crítica de la razón funcionalista. Tradução de Manuel Jiménez Redondo. Madrid: Taurus. 2003b.

HABERMAS, Jürgen. Verdade e justificação: ensaios filosóficos. Tradução de Milton Camargo Mota. São Paulo: Loyola. 2004.

HABERMAS, Jürgen. Entre naturalismo e religião. Tradução de Flávio Beno Siebeneichler. Rio de Janeiro: Tempo Brasileiro. 2007.

HABERMAS, Jürgen. Teoria do agir comunicativo. São Paulo: Martins Fontes, 2012. 2 v.

PIZZI, Jovino. Ética do discurso: a racionalidade ética-comunicativa. Porto Alegre: EDIPUCRS. 1994.

PIZZI, Jovino. O conteúdo moral do agir comunicativo. São Leopoldo: Unisinos. 2005.

HERMANN, Nadja. Ética \& educação. Outra sensibilidade. Belo Horizonte: Autêntica, 2014.

SIEBENEICHLER, Flavio Beno. Jürgen Habermas: razão comunicativa e emancipação. Rio de Janeiro: Tempo Brasileiro. 1990.

SIEBENEICHLER, Flavio Beno. O papel da análise genealógica no cognitivismo moral de J. Habermas. Ethica-Cad. Acad. Rio de janeiro, v.5, n.2, p. 24-40. 1998.

SIEBENEICHLER, Flavio Beno. A ética do discurso à luz das revisões dos seus fundadores pós-kantianos. Ethica-Cad. Acad. Rio de janeiro, v.7, n.2, p. 37-51, 2000. 